\title{
UK Renal Registry 11th Annual Report (December 2008): Chapter 2 Introduction to the 2008 UK Renal Registry Report
}

\author{
David Ansell $^{\mathrm{a}}$ and Charles R V Tomson ${ }^{\mathrm{a}}$ \\ aUK Renal Registry, Bristol, UK
}

\section{Key Words}

UK Renal Registry

\section{Introduction}

The UK Renal Registry (UKRR) is part of the UK Renal Association and provides independent, professionally led, audit and analysis of renal replacement therapy (RRT) in the UK. The Registry is funded directly by participating renal centres through an annual capitation fee, currently $£ 17$ per patient per annum (2008).

The Registry receives quarterly electronic data extracts from information systems used for clinical and administrative purposes within each renal centre and has developed expertise in mapping data items from each local system to the UKRR database. All but one UK renal centre provided an electronic data extract in 2007; although this centre provided summary data on prevalent patients.

\section{Renal centre populations}

The Scottish Renal Registry provided demographic and also haematology and dialysis dose data from the whole of Scotland.
The populations listed below are extremely crude estimates of the population coverage of each renal centre (based on each individual renal centre's own estimate). Work is currently underway to redefine this using geographical mapping of patient populations.

For a list of the IT systems currently used by these centres refer to chapter 15 .

Two renal centres were created in 2007 and one is planned for 2009.

1. Doncaster (until 2007 a satellite of Sheffield renal centre)

2. Colchester (new 2007)

3. Hereford (until 2009 a satellite of Birmingham, Queen Elizabeth Hospital)

In the 2007 Report, Chester was incorrectly reported as a new centre, it actually remained part of the Wirral renal centre.

\section{Future coverage by the Registry}

From the analyses presented here, it can be seen that the report on the 2007 data covers over $99 \%$ of the UK with Colchester the only renal centre unable to return an electronic data extract. This interface is currently being developed. 
Table 2.1. Centres in the 2007 Registry Report

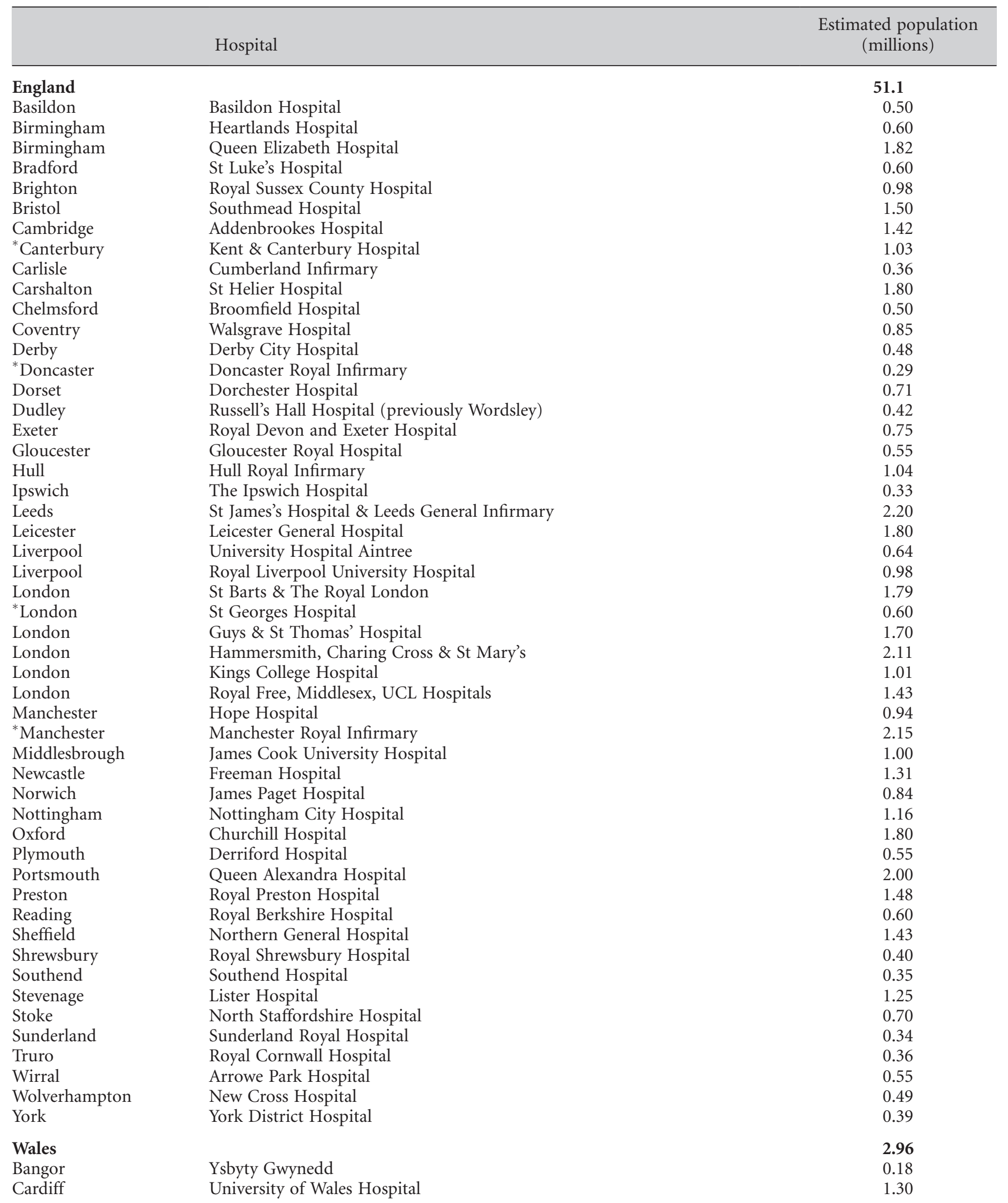


Table 2.1. Continued

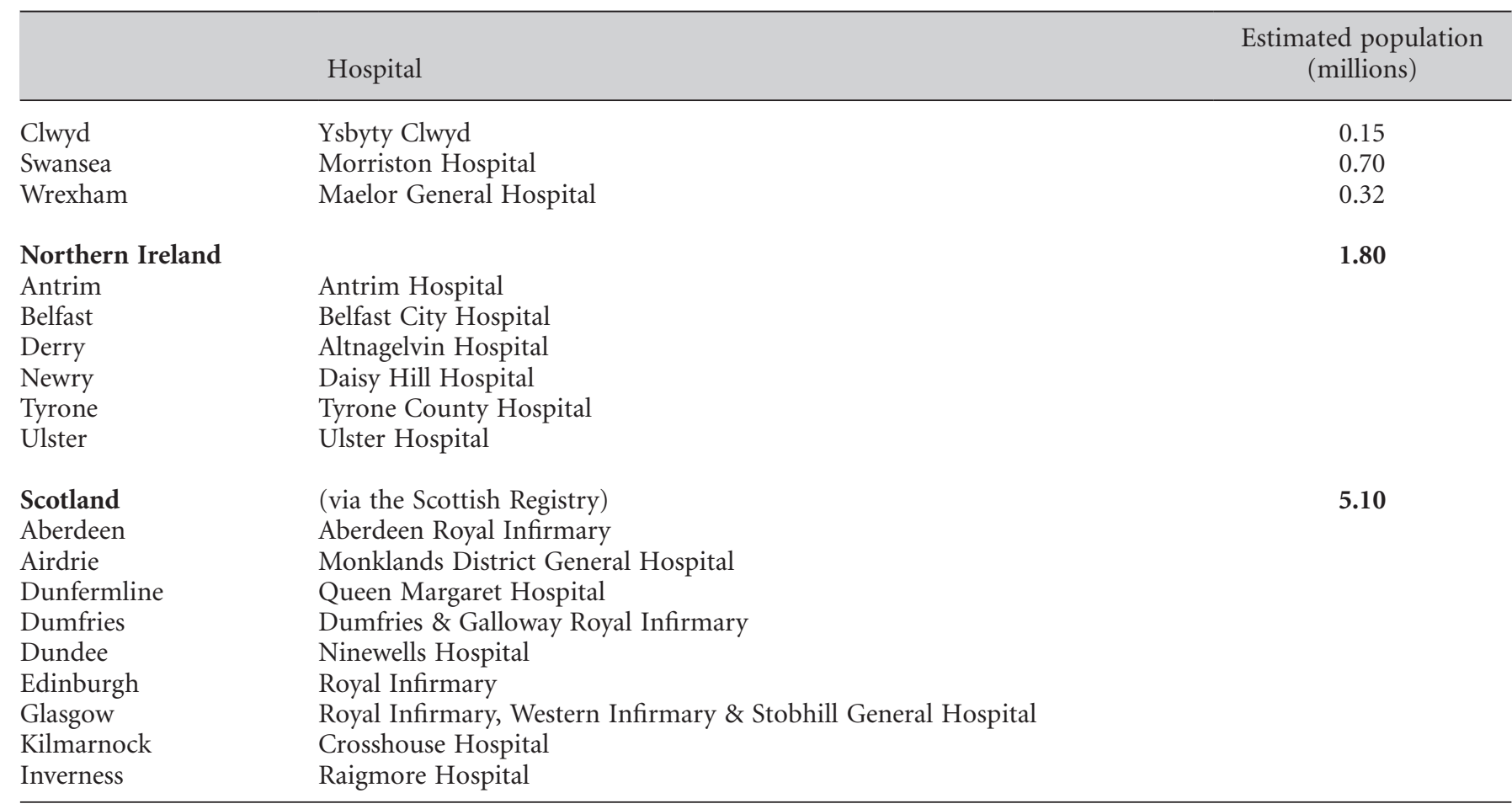

${ }^{*}$ Renal centre included in the report for the first time

\section{Completeness of returns for four important data items}

The Registry has again included a table of completeness for four of the important data items for which it has been trying to improve returns. Centres have been ranked on their average score (table 2.2). Ethnicity, date first seen by nephrologist and comorbidity are not mandatory items in the Scottish Renal Registry returns so these centres have been listed separately.

\section{Software and links to the Registry}

There are 13 systems in use by renal centres, some of them commercial and some developed in-house. The Registry has worked with the relevant companies to provide appropriate software links to the Registry. As new data items (e.g. those relating to vascular access) are defined and the need for collection by the Registry accepted, there will be a continuing requirement that these companies provide the necessary enhancements to their systems to permit collection of these items and maintenance of the interface with the Registry for transmission of the new items. The Standards Board of the
NHS Information Centre has approved a National Renal Dataset, with the intention that collection of these data items within electronic care records provided by Local Service Providers under Connecting for Health will be mandatory (see chapter 15).

\section{Paediatric Renal Registry links}

In the UK at the start of 2008 there were 875 patients under 18 years old who were on renal replacement therapy at the 13 UK paediatric renal centres. In order to integrate with the adult Registry and also benefit from funded resources for data management, the BAPN is combining with the adult Registry and will implement similar automated electronic data capture systems.

\section{Relationship with the Renal Association}

The UK Renal Registry Chairman represents the UKRR on the Renal Association Clinical Practice Guidelines Committee. This committee has produced a modular, 
Table 2.2. Percentage completeness of data returns

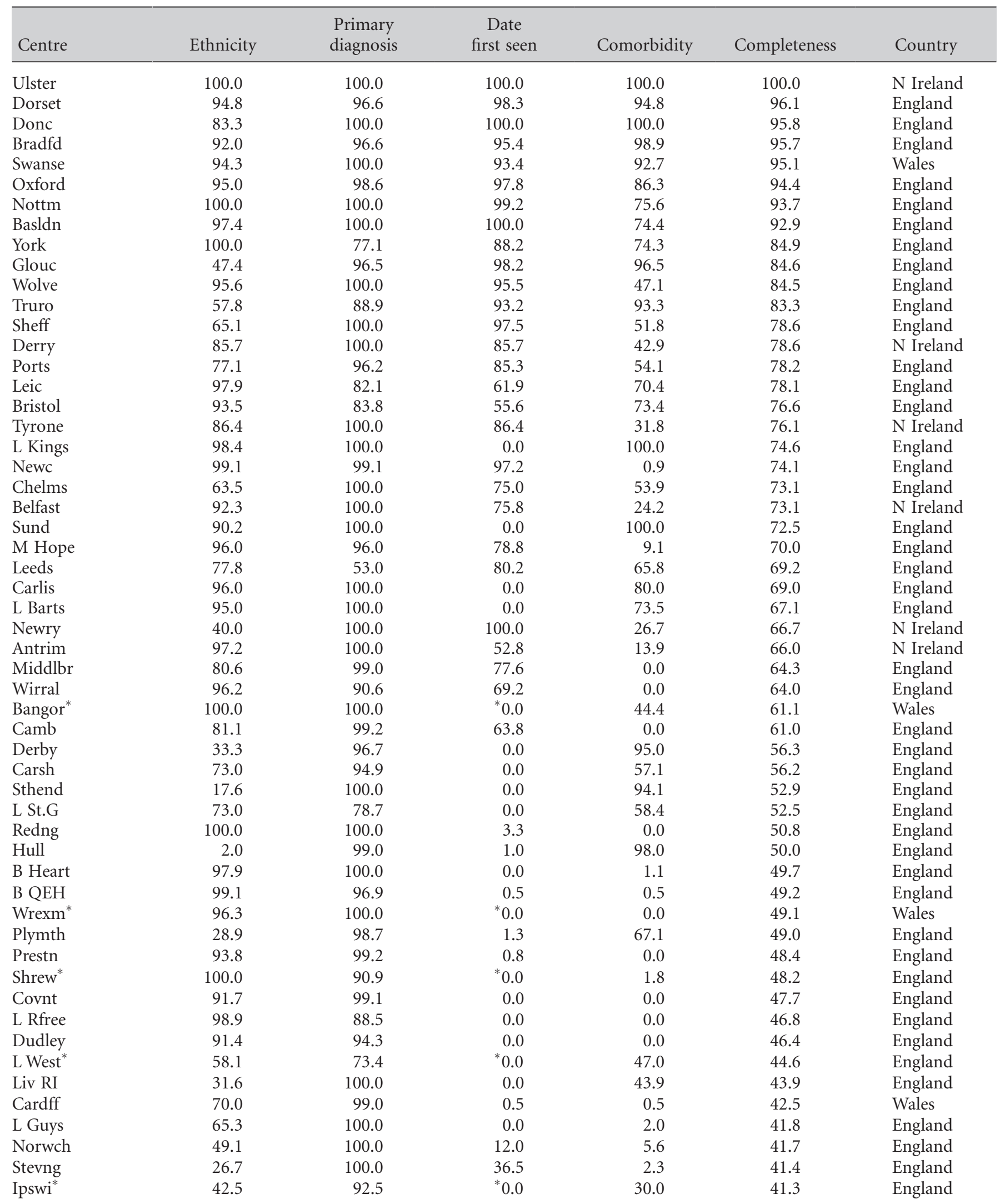


Table 2.2. Continued

\begin{tabular}{|c|c|c|c|c|c|c|}
\hline Centre & Ethnicity & $\begin{array}{l}\text { Primary } \\
\text { diagnosis }\end{array}$ & $\begin{array}{c}\text { Date } \\
\text { first seen }\end{array}$ & Comorbidity & Completeness & Country \\
\hline Stoke* & 8.0 & 98.9 & ${ }^{*} 0.0$ & 43.7 & 37.6 & England \\
\hline Liv Ain & 35.3 & 100.0 & 0.0 & 2.9 & 34.6 & England \\
\hline M RI & 93.7 & 32.7 & 11.3 & 0.0 & 34.4 & England \\
\hline Clwyd & 4.3 & 95.7 & 0.0 & 0.0 & 25.0 & Wales \\
\hline Edinb & 1.1 & 100.0 & & & & Scotland \\
\hline D \& Gall & 0.0 & 100.0 & & & & Scotland \\
\hline Airdrie & 0.0 & 98.0 & & & & Scotland \\
\hline Inverns & 4.0 & 96.0 & & & & Scotland \\
\hline Glasgw & 0.5 & 91.9 & & & & Scotland \\
\hline Dunfn & 0.0 & 91.9 & & & & Scotland \\
\hline
\end{tabular}

* All first seen dates have been set to missing as at least $20 \%$ of the dates returned were the same as the treatment start date

4th edition set of audit measures relating to all aspects of care of patients with kidney disease (http://www.renal. org/pages/pages/guidelines/current.php). Where possible, the UKRR will adapt its data collection procedures so as to be able to report on performance against these audit measures. Some of the data items cannot be collected electronically from renal centre IT systems and for those measures, centres will have to develop local audits. The Chairman also represents the UKRR on the Clinical Affairs Board.

\section{Links with other organisations}

UK Transplant and the British Transplantation Society Close collaboration has developed with UK Transplant (www.nhsbt.nhs.uk) and with the British Transplantation Society (www.bts.org.uk), to produce analyses utilising the coverage of both the NHS BT and Renal Registry databases. The 2007 Report included many new analyses and others have been accepted as papers for publication in peer reviewed journals. A pdf copy of the transplant chapter was distributed to all on the BTS membership list.

Departments of Health and predicting future RRT demand

Registry reports are sent to the Department of Health $(\mathrm{DoH})$ or equivalent body in each UK country in the expectation that the analyses will inform policy relating to the care of patients with established renal failure. Such analyses were important in the development of the National Service Framework in England. The DoH for England is represented on the UKRR Committee.

The Registry is currently working closely with the DoH on producing a new model of predicting future RRT demand by modalities and Primary Care Trust (PCT), adjusting for factors such as age, ethnicity and social deprivation. The first model was produced by Roderick et al. and published in the 2002 Registry Report chapter 6, although the Registry data available at that time was insufficient to include adjustment for these demographic factors. The final model will be freely available to all commissioners and providers.

The Information Centre, Connecting for Health, and the Secondary Uses Service

The Registry, together with other professional organisations, provided input into a working party to define the scope of an audit of care of patients with kidney disease in England. The funding for the audit was awarded by the Healthcare Commission (now renamed as the Healthcare Quality Improvement Partnership) to the NHS Information Centre (NHS IC) in association with the Registry. The national audit of vascular access for haemodialysis is ongoing and the audit on patient transport was undertaken in 2008. 
Detailed negotiation continues with the Information Centre on how data will flow to the UKRR as the work of Connecting for Health ( $\mathrm{CfH})$ evolves. The present model of data extraction from specialty-specific IT systems in each renal centre, would not be sustainable if such specialty-specific systems were no longer supported or used. CfH has now taken the view that specialty-specific systems, fully inter-operable with the main electronic care record, will continue to be necessary to support the care of patients within different medical specialties.

The Registry is keen, to be able to use data from the NHS IC on hospitalisation, surgical procedures and discharge diagnoses and is investigating obtaining the required approval from the Secretary of State to obtain this data linkage.

\section{The Health Protection Agency}

Web-based collection of an extended dataset by the Health Protection Agency (HPA) on patients on RRT with methicillin resistant Staphylococcus Aureus (MRSA) bacteraemia was piloted in eight renal centres in 2006-7. This programme is now being extended to the whole of England. The Registry has collaborated with the HPA and the Cleaner Hospitals Team of the Department of Health for England in providing details of main centres and satellite units, to ensure that all patients on RRT developing MRSA bacteraemia can be accurately identified. Together with the HPA, the first joint report on bacteraemias in renal patients in England, is included in chapter 12 .

\section{EDTA-ERA Registry}

The UKRR sends fully anonymised data to the European Renal Association Registry. Several representatives have participated in discussions regarding the ERA nephroQUEST programme for European countries, which intends to initiate quality initiatives, similar to many of those already undertaken by the UKRR. The nephroQUEST initiative has been granted funding by the European Union and will involve the specification and development of a standardised renal IT data interface for electronic exchange of data (HL7v3). The nephroQUEST group is also investigating the feasibility of funding and co-ordinating pan-European collaboration in anaemia, mineral metabolism and cardiovascular risk studies.

The ERA Registry will finalise a new, more comprehensive, primary renal diagnosis coding system in May 2009.

\section{Commissioning of renal services and Primary Care Trusts/Health Authorities}

An Executive summary of the Annual Report is published (as a pdf file) and distributed to all specialised commissioners in the UK. Feedback has been positive.

The East Midlands Public Health Observatory (www.empho.org.uk) has a statutory responsibility on reporting to the Department of Health for England on renal services. The UKRR is working with them to provide a web based geographical output (by PCT for England and Health Authority for other UK countries) of much of the Registry output.

\section{The Registry and clinical governance}

This is reported on in chapter 15.

\section{Anonymity and confidentiality}

This is reported on in chapter 15.

\section{Data security and confidentiality}

Data encryption systems and data security are described in chapter 15.

The National Health Service Act 2006 section 251 and the Health and Social Care Act 2001: section 60 exemption

This is reported on in chapter 15.

\section{New data items and analyses}

\section{Pre-RRT care}

In order to provide some description of the care prior to start of RRT, the Registry is extending the dataset to include retrospective data from prior to starting RRT (time points 1, 2, 3, 6, 9 and 12 months). This has now been tested at 8 centres and some preliminary analyses have been made available. 
Vascular access and PD access

As part of the testing of the National Renal Dataset, UK nephrologists have supported the Registry in developing definitions of data items to describe the construction and use of both vascular access for haemodialysis and PD access. Implementation of the HQIP vascular access audit will result in these data fields becoming available on all renal IT systems. Additionally the pre-specified data items for PD access and complications may also be installed on renal IT systems at the same time as the vascular access software upgrades.

\section{Non-RRT care of patients with stage 5 CKD}

The Registry has been awarded funding from Kidney Research UK and the Edith Murphy Foundation to run a pilot project in 8 renal centres, involving collection of data on patients with stage $5 \mathrm{CKD}$ who are not currently receiving RRT. Data will include laboratory variables, comorbidity, the patient's decision about future RRT (if possible), any form of RRT subsequently initiated and the date and cause of death. If successful, these data will allow analysis of the outcomes of 'conservative', 'palliative' or 'supportive' care as well as an estimate of how many patients enter this pathway.

\section{New data items}

The Registry has previously produced analyses on phosphate control, lipid control and blood pressure achievement. These analyses are now limited due to the absence of information on medications. The Registry is expanding the dataset to collect this information.

One of the other missing factors is the date on which these measurements were taken (for analyses on HD patients, relating the data to the day of the week). The dataset extraction is being altered to incorporate this. At the same time the quarterly data extraction process will be modified to include monthly laboratory items where available (e.g. up to 3 results per data item per quarter). This additional modification will also be important to the incorporation of CKD 5 patients who are not on RRT.

\section{Peritoneal dialysis}

The Registry Committee is acutely aware of the limitations of its analyses on the outcomes of peritoneal dialysis. The Registry is unable to report on membrane function, peritonitis rates, residual renal function, prescription of peritoneal dialysis, net ultrafiltration or delivered peritoneal dialysis dose. Other registries have reported on these, for instance the ANZDATA Registry has reported on the association between peritoneal transport status and outcome (Rumpsfeld M, McDonald SP, Johnson DW). Higher peritoneal transport status is associated with higher mortality and technique failure in the Australian and New Zealand peritoneal dialysis patient populations (J Am Soc Nephrol 2006;17:271-278) and the outcome of peritoneal dialysis after failed kidney transplantation (Badve SV, Hawley CM, McDonald SP, Mudge DW, Rosman JB, Brown FG, Johnson DW: Effect of previously failed kidney transplantation on peritoneal dialysis outcomes in the Australian and New Zealand patient populations. Nephrol Dial Transplant 9:9, 2005). With the publication of revised peritoneal dialysis clinical practice guidelines by the Renal Association (http://www.renal.org/guidelines/module3b. html), it is time to put this right.

The problem is not due to a lack of willingness of the Registry to report on these data items - the relevant fields have been defined in the Registry dataset for years. The Registry has written software within Proton to support the calculation of PD KT/V and PET testing. Uptake to use this software by PD teams at Proton sites rather than their commercial standalone PC based systems has been poor. Other non-Proton based renal system IT suppliers have also not integrated such a product into their software having focused, at least initially, on haemodialysis rather than peritoneal dialysis. The calculations required are also more complex in peritoneal dialysis than in haemodialysis; whereas urea reduction ratio can be calculated simply from the predialysis and post-dialysis urea concentration, calculation of peritoneal dialysis dose requires 13 pieces of information, including the results of biochemical tests on each exchange, drain volumes, plasma biochemistry, height, weight and residual renal function. Consistent practice between centres is also required in measurement of dialysis dose in APD patients, accounting for overfill in the calculation of ultrafiltration in CAPD patients and the correction for glucose interference in the measurement of dialysate creatinine concentration. Reliance on commercially provided software for calculation of dialysis dose is not a solution, since different software packages use different approaches to this calculation.

The UK Peritoneal Dialysis Research Network was formed to study encapsulating peritoneal sclerosis, but is now developing a clinical tool, derived from the 
GLOBAL fluid study (http://medweb.uwcm.ac.uk/ globalfluid/), which accommodates different clinical practices and which will use methods of calculation recommended by the Renal Association Clinical Practice Guidelines committee. It is anticipated that this network will provide a series of recommendations for the uniform collection of relevant data items in each centre, which will lead rapidly to the development of an agreed dataset in a uniform electronic format suitable for extraction and analysis by the Registry.

\section{Support for renal systems managers and informatics staff}

For the last 3 years the Registry has provided a forum for a renal informatics meeting supporting development of renal IS \& IT staff. Topics included a discussion on current informatics, health informatics professionalism (e.g. UKCHIP), agenda for change and informatics related job profiles, ways to enhance the role of IS managers within the multi-disciplinary team, an update from the NHS Information Centre on the national IT programme, provision by the UKRR of centre specific reports and examples of local renal audits. Encouraged by the feedback from those who attended, the Registry is planning a further meeting for September 2009.

\section{Interpretation of the data within the report}

It is important to re-emphasise that for the reasons outlined below, caution must be used in interpretation of any apparent differences between centres.

As in previous reports, the $95 \%$ confidence interval is shown for compliance with a Standard. The calculation of this confidence interval (based on the Binomial distribution) and the width of the confidence interval depends on the number of values falling within the Standard and the number of patients with reported data.

To assess whether there is an overall significant difference in the percentage reaching the Standard between centres, a Chi-squared test has been used. Caution should be used when interpreting 'no overlap' of $95 \%$ confidence intervals between centres in these presentations. When comparing data between many centres, it is not necessarily correct to conclude that two centres are significantly different if their 95\% confidence intervals do not overlap. In this process, the eye compares centre $\mathrm{X}$ with the other 70 centres and then centre Y with the other 69 centres. Thus, 139 comparisons have been made and at the commonly accepted 1 in 20 level at least 7 are likely to appear 'statistically significant' by chance. If 71 centres were compared with each other, 2,484 such individual comparisons would be made and one would expect to find 124 apparently 'statistically significant' differences at the $\mathrm{p}=0.05$ level and still 25 at the $\mathrm{p}=0.01$ level. Thus, if the renal centres with the highest and lowest achievement of a standard are selected and compared, it is probable that an apparently 'statistically significant result' will be obtained. Such comparisons of renal centres selected after reviewing the data are statistically invalid. The Registry has therefore not tested for 'significant difference' between the highest achiever of a standard and the lowest achiever, as these centres were not identified in advance of looking at the data.

The most appropriate way of testing for significance between individual centres, to see where the differences lie, is not clear. The commonly used Bonferroni test is not applicable to these data, since the individual comparisons are not independent. In several chapters, funnel plots are used to identify significant outliers outside 2 and 3 standard deviations (see chapters 3, 4, 8, 9 and 11).

In chapters 3 and 4 , charts are presented to allow PCTs and other organisations representing relatively small populations to assess whether their incidence and prevalence rates for renal failure are significantly different from that expected from the age and ethnic mix of the population they serve.

\section{Future potential}

\section{Support for renal specialist registrars undertaking a} non-clinical secondment

Through links with the Universities of Southampton and Bristol, training is available in both Epidemiology and Statistics. The Renal Registry now has the funding for 3 registrar positions. Dr Daniel Ford started in August 2007 and Dr Alex Hodsman and Dr Udaya Udayaraj are just completing 3 years working with the Registry both studying for higher degrees. In 2009 their positions will be taken by Dr Clare Castledine and Dr Lynsey Webb. 
Dr Raman Rao, Dr Az Ahmad, Dr Alison Armitage, Dr Catherine Byrne and Dr J Rajamahesh have previously completed two years working as a Registry registrar. It is hoped that their positive experiences and publication record will encourage other registrars who are interested in undertaking epidemiological work to consider working with the Registry.

\section{Recent UK Renal Registry peer reviewed publications}

1 Udayaraj UP, Steenkamp R, Caskey FJ, Rogers C, Nitsch D, Ansell D, Tomson CR. Blood pressure and mortality risk on peritoneal dialysis. Am J Kidney Dis. 2009 Jan;53(1):70-8. Epub 2008 Nov 22.

2 Couchoud C, Jager KJ, Tomson C, Cabanne JF, Collart F, Finne P, de Francisco A, Frimat L, Garneata L, Leivestad T, Lemaitre V, Limido A, Ots M, Resic H, Stojceva-Taneva O, Kooman J. Assessment of urea removal in haemodialysis and the impact of the European best practice guidelines. On behalf of the QUEST working group on dialysis adequacy. Nephrol Dial Transplant. 2008 Nov 27.

3 Tomson C, Ford D, Ansell D. The UK Renal Registry: an overview. Br J Hosp Med (Lond). 2008 Oct;69(10):548-9.

4 Tangri N, Ansell D, Naimark D. Predicting technique survival in peritoneal dialysis patients: comparing artificial neural networks and logistic regression. Nephrol Dial Transplant. 2008 Sep;23(9):2972-81. Epub 2008 Apr 25.

5 Nitsch D, Burden R, Steenkamp R, Ansell D, Byrne C, Caskey F, Roderick P, Feest T. Patients with diabetic nephropathy on renal replacement therapy in England and Wales. QJM. 2007 Sep;100(9): 551-60. Epub 2007 Aug 6.

6 van Manen JG, van Dijk PC, Stel VS, Dekker FW, Cleries M, Conte F, et al. Confounding effect of comorbidity in survival studies in patients on renal replacement therapy. Nephrol Dial Transplant 2007;22(1):187-95.

7 Ansell D, Udayaraj UP, Steenkamp R, Dudley CR. Chronic Renal Failure in Kidney Transplant Recipients. Do They Receive Optimum Care?: Data from the UK Renal Registry. Am J Transplant. 2007 May;7(5):1167-76.

8 Caskey FJ, Roderick PJ, Steenkamp R, Nitsch D, Thomas K, Ansell D, Feest TG. Social deprivation and survival on renal replacement therapy in England and Wales. Kidney International 2006;70:2134-2140.

9 White P, James V, Ansell D, Lodhi V, Donovan KL. Equity of access to dialysis facilities in Wales. Qjm 2006;99(7):445-52.

10 Ahmad A, Roderick P, Ward M, Steenkamp R, Burden R, O’Donoghue $\mathrm{D}$, et al. Current chronic kidney disease practice patterns in the UK: a national survey. Quarterly Journal of Medicine 2006;23:23.

11 Caskey FJ, Schober-Halstenberg HJ, Roderick PJ, Edenharter G, Ansell $\mathrm{D}$, Frei $\mathrm{U}$, et al. Exploring the differences in epidemiology of treated ESRD between Germany and England and Wales. Am J Kidney Dis. 2006; 47(3):445-54.

12 Van Dijk PC, Jager KJ, Stengel B, Gronhagen-Riska C, Feest TG, Briggs JD. Renal replacement therapy for diabetic end-stage renal disease: data from 10 registries in Europe (1991-2000). Kidney Int 2005;67:1489-99.

13 Roderick P, Nicholson T, Armitage A, Mehta R, Mullee M, Gerard K, et al. An evaluation of the costs, effectiveness and quality of renal replacement therapy provision in renal satellite units in England and Wales. Health Technol Assess 2005;9:1-178.

14 Blank L, Peters J, Lumsdon A, O’Donoghue DJ, Feest TG, Scoble J, Wight JP, Bradley J. Regional differences in the provision of adult renal dialysis services in the UK. Quarterly Journal of Medicine 2005;98:183-190.

15 Feest TG, Rajamahesh J, Byrne C, Ahmad A, Ansell A, Burden R, Roderick R. Trends in adult renal replacement therapy in the UK: 1982-2002. Quarterly Journal of Medicine 2005;98:21-28.
16 Tangri N, Ansell D, Naimark D. Lack of a centre effect in UK renal units: application of an artificial neural network model. Nephrol Dial Transplant. 2006;21:743-8.

17 Stel VS, van Dijk PC, van Manen JG, Dekker FW, Ansell D, Conte F, et al. Prevalence of co-morbidity in different European RRT populations and its effect on access to renal transplantation. Nephrol Dial Transplant. 2005;20:2803-11.

18 Roderick P, Nicholson T, Mehta R, Gerard K, Mullee M, Drey N, Armitage A, Feest T, Greenwood R, Lamping D, Townsend J. A clinical and cost evaluation of hemodialysis in renal satellite units in England and Wales. Am J Kidney Dis. 2004;44:121-31.

19 Roderick P, Davies R, Jones C, Feest T, Smith S, Farrington K. Simulation model of renal replacement therapy: predicting future demand in England. Nephrol Dial Transplant. 2004;19:692-701.

20 Burton C, Ansell D, Taylor H, Dunn E, Feest TG. Management of anaemia in United Kingdom renal units: a report from the UK Renal Registry. Nephrology, Dialysis, Transplantation 2000;15:1022-1028.

\section{The following have been submitted for publication:}

1 A V R Rao, D Ansell, J A Gilg, S J Davies, E J Lamb, C R V Tomson. Effect of change in renal replacement therapy modality on laboratory variables: a cohort study from the UK Renal Registry.

2 D Nitsch, L Kadala, P Mangtani, R Steenkamp, D Ansell, C Tomson, I dos Santos Silva, P Roderick. Validation and utility of a computerized South Asian Names and Group Recognition Algorithm (SANGRA) in ascertaining South Asian ethnicity in the national renal registry.

3 I Macdougall, C Tomson, David Ansell. Relative risk of death in UK haemodialysis patients in relation to achieved haemoglobin from 1999 to 2005: an observational study using UK Renal Registry data incorporating 33,373 patient-years of follow-up.

4 U Udayaraj, Y Ben-Shlomo, P Roderick, A Casula, D Ansell, C Tomson, F Caskey. Socioeconomic status, ethnicity and geographical variations in incidence of renal replacement therapy in England and Wales - an ecological study.

5 L Karamadoukis, D Ansell, R Foley, S McDonald, C Tomson, L Trpeski, F Caskey. Towards casemix-adjusted international renal registry comparisons: how can we improve data collection practice?

\section{Commissioned research and reports}

1 Feest T, Rajamahesh J, Taylor H, Roderick P. The Provision of Renal Replacement Therapy for adults in the UK 1998. 1998 National Renal Survey, Report for Department of Health.

2 Roderick P, Armitage A, Feest TG, et al. An evaluation of the effectiveness, acceptability, accessibility and costs of renal replacement therapy in renal satellite units in England and Wales. Report for Department of Health, 2003.

3 Roderick P, Davies R, Jones C, Feest T, Smith S, Farrington K. Simulation model of renal replacement therapy: predicting future demand in England. HTA report 2003.

4 Feest TG, Byrne C, Ahmad A, Roderick P, Webber S, Dawson P. The Provision of Renal Replacement Therapy in the UK 2002. Report for the Department of Health, 2004.

5 Ansell D, Benoy-Deeney F, Dawson P, Doxford H, Will E. Welsh data validation exercise project report. Report for the Welsh Assembly 2005. 


\section{Distribution of the Registry Report}

This report will also be distributed to Strategic Health Authorities and all PCTs in England and Commissioners throughout the UK.

Further copies of the report will be sent to individuals or organisations on request: a donation towards the $£ 15$ cost of printing and postage will be requested. CDs will also be available. The full report may be downloaded from the Registry website, www.renalreg.org.

Conflict of interest: none 